\title{
The role of diet and probiotics in prevention and treatment of bacterial vaginosis and vulvovaginal candidiasis in adolescent girls and non-pregnant women
}

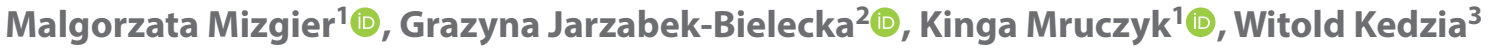 \\ ${ }^{1}$ Dietetic Division Faculty of Physical Culture in Gorzow Wlkp., Poznan University of Physical Education, Gorzow Wlkp., Poland \\ ${ }^{2}$ Division of Developmental Gynecology and Sexology, Department of Perinatology and Gynecology, \\ Poznan University of Medical Sciences, Poland \\ ${ }^{3}$ Department of Perinatology and Gynecology, Gynecology Clinic, Poznan University of Medical Sciences, Poland
}

\begin{abstract}
The article raises important issues regarding the use of diet and probiotics in prevention and treatment of vaginitis.

Vaginitis is defined as any condition with symptoms of abnormal vaginal discharge. The most common causes of vaginitis are vulvovaginal candidiasis (VVC), trichomoniasis and bacterial vaginosis (BV). Vaginitis has been linked to itching, burning, pain, discharge, irritation and also adverse reproductive and obstetric health outcomes. Moreover, microorganisms that build vaginal flora in the state of bacterial vaginosis are a source of cervicitis and endometritis (often in subclinical forms) and pelvic inflammatory disease (PID)

The proper diet and probiotics consumption may influence the composition of the gut microbiota, improve gut integrity, and have an impact on maintaining and recovering the normal vaginal microbiota.

Future studies and reviews investigating the role of diet and probiotics in changes to gut and vaginal microbiome need to focus on deciphering the mechanismus of host bacteria interaction in vulvovaginal health.
\end{abstract}

Key words: vaginal infections; vaginitis; bacterial vaginosis; vulvovaginal candidiasis; diet; probiotics; prebiotics

Ginekologia Polska 2020; 91, 7: 412-416

\section{INTRODUCTION}

In adolescent girls and non-pregnant women, especially with a decrease in immunity, vaginitis, including fungal infections, can occur, which clinically manifests as abnormal vaginal discharge, irritation, itching, burning, discomfort. Sexually transmitted diseases are a particularly problematic in women [1-9].

Vaginitis is a general term that refers to inflammation of the vaginal wall, generally caused by one of three disorders: yeast infections, bacterial vaginosis or trichomoniasis. The normal bacterial flora of the vagina and cervix protect against the development of pathogenic strains, while abnormal flora tend to be the most common starting point for the development of infections.

During adolescence, bacterial vaginosis episodes affect $3-7 \%$ of non-sexually related and $4-15 \%$ of sexually active girls 13-18 years of age. This is a significant problem, because the microorganisms that build vaginal flora in the state of bacterial vaginosis are a source of cervicitis and endometritis (often in subclinical forms) and pelvic inflammatory disease (PID) [1-8].

\section{ETIOLOGY}

Female genitalia are a natural biotope for commensal flora. Proper biocenosis of the genital environment determines protection against the development of inflammatory processes. Anatomical and physiological conditions of the genital organs - moisturizing and the proximity of the urethra and anal opening - favor the development of infection. Genital inflammation is most often caused by neglecting hygiene, mechanical injury or infection (viruses, chlamydia, fungi, protozoa). A certain group of these inflammations also 
occurs on an allergic basis (e.g. allergy to cleaning products). The most common causes of vaginitis are bacterial vaginosis (Bacterial vaginosis, BV), vulvar and vaginal candidiasis (Vulvovaginal candidiasis, VVC) and trichomoniasis. BV is involved in $40 \%$ to $50 \%$ of cases when the cause is identified, VVC accounts for $20 \%$ to $25 \%$, and trichomoniasis accounts for $15 \%$ to $20 \%$ of vaginitis. Non-infectious causes, including atrophic, irritating, inflammatory and allergic vaginosis occur less frequently and account for $5 \%$ to $10 \%$ of cases of vaginitis [2]. The effectiveness of defense mechanisms and their mutual compensation is different in different periods of a woman's life, which is hormonally determined $[1-8,10]$. The vaginal microflora also changes during menstrual bleeding [11].

In the female newborn, who is still under the influence of estrogens from the period of intrauterine life, the $\mathrm{pH}$ of the vagina after colonization with acid-forming rods (Lactobacillus acidophilus) is acidic. In the subsequent months of the girl's life, the level of estrogen gradually decreases. The vaginal epithelium consists only of the basal and basal layers, without glycogen grains in the cells, which determines the development of acid-forming bacilli - the $\mathrm{pH}$ changes. During the so-called estrogenic silence, which lasts until the onset of puberty, the $\mathrm{pH}$ changes to neutral, at which time, the mixed bacterial flora of grains and sticks settles. A narrow vagina, adhesion of its walls, the presence of the hymen and the vaginal folds (plicae palmatae) constitute a mechanical compensation for the described lack of biochemical defenses during this period of life. During puberty, the concentration of estrogens increase and the vaginal epithelium becomes multilayered. The intermediate layer cells contain glycogen, which allows the development of acid-forming bacilli and prevents the settlement of pathogenic microorganisms. A mature woman develops further defenses. These include the intensification of the process of exfoliation of genital epithelial cells, the formation of secretion, which is removed actively (e.g., epithelial shutter epithelium) or passively along with microorganisms and cell debris, as well as a specific $\mathrm{pH}$ value on individual genital floors. In girls who have not had sexual intercourse, inflammation of the internal genital organs occurs relatively rarely, although descending (purulent tonsils, teeth) or through continuity (appendicitis) is also possible. Regardless of the age group analyzed, inflammatory problems in the genitals most often relate to vulvovaginitis [1-8]

This inflammation can be caused by viruses, chlamydia, bacteria, fungi (most often Candida Albicans), and vaginal trichomes (Trichomonas Vaginalis). Some authors also recognise non-specific vulvovaginitis. Genital infections can be caused by endogenous vaginal bacterial flora or by exogenous bacterial flora (sexually transmitted and extrinsic) $[1,5,7,12]$.

In girls and women who have started sexual intercourse, an increase in vulvovaginitis and, as a result, an increase in internal genital inflammation due to the ascending route is observed $[1,5,7,12]$.

This review aimed to determine the role of proper diet and probiotics and prebiotics use in relation to therapy and profilaxis of vulvovaginal candidiasis (VVC) and bacterial vaginosis (BV) in non-pregnant women and girls.

\section{THE ROLE OF DIET IN PREVENTION OF BV AND VVC}

Numerous studies have proven that diet is a key modifiable factor affecting the composition of the intestinal microflora [12-21].

It is also known that educating patients in the field of balancing the diet (reducing the consumption of sweets, increasing the consumption of vegetables, fruits and dairy products) has a significant role in the treatment of vaginitis [14].

The use of functional foods and supplements containing probiotics and prebiotics has a beneficial effect on genital inflammation $[3,9]$.

From the point of view of the proper function and prevention of inflammation, it is important that the genital organs receive metabolism products from the blood: fats, proteins and carbohydrates. From metabolic products obtained through blood vessels, mucus is produced, which is necessary for proper vaginal hydration. Unfortunately, the predominance of carbohydrates, especially simple sugars, promotes the development of abnormal vaginal flora and conditions become favorable for the development of yeast-like fungi [14-16].

To prevent inflammation, it is important to create an appropriate intestinal barrier. For protect the vaginal environment properly against excessive multiplication of pathogenic microorganisms, including yeast-like fungi, it is therefore important to have a properly balanced diet, low glycemic load, low fat, containing folic acid, vitamins D, E, $C, A$ and beta carotene, as well as products rich in calcium and betaine [14-16].

An unbalanced diet can be a risk factor for BV. Women tend to be more exposed to $B V$ if they have poor micronutrient status, including vitamins $A, E, D, C$ and beta carotene — indicating a lower fruit and vegetable intake. In recent years, scientists have found that the richer the diet is in nutrients, the lower the risk of apparent bacterial infection. Routine consumption of dairy products and fresh fruit and vegetables reduces the likelihood of vaginitis, while eating sweets increases the likelihood [14-16].

Sweets and other carbohydrate sources can affect the human glycemic response. Chronic and continuous exposure to hyperglycemia after a meal can have an adverse effect on health and has been linked to oxidative damage by its reducing plasma antioxidant defense and increasing inflammation due to free radical production. It is possible that chronic exposure to diets with high energy value and 
high energy density can affect host responses to bacterial colonization, particularly BV pathogenesis, through oxidative stress and impaired immune function [16].

Yasmin et al. proved that increased dietary fat intake (39\% of energy from fat), especially total fat, saturated fat and monounsaturated fat, can increase vaginal $\mathrm{pH}$, thus increasing the risk of bacterial vaginosis. In addition, dietary fat may be a factor that inhibits the immune functions of the intestinal mucosa. It is likely that a high dietary fat intake may affect the mucosal immune system and thus increase the risk of bacterial infections associated with BV.The studies cited did not show a relationship between BV and carbohydrate or protein intake, and this means that high fat intake is a predictor of BV independent of energy intake [16-18].

A proper calcium supply is also important in preventing inflammation in women and girls. Genital infections are more common in cases where there are low levels of calcium in the body. The sources of calcium are milk and dairy products such as cheese or yogurt, but also legumes (e.g. white beans), seeds (e.g. sesame) and dark green vegetables (such as broccoli or spinach). Yasmin et al. proved significant inverse relationships between severe BV and calcium intake, as well as with folic acid, and vitamin E [18].

With the weakening of the immune system in women and girls, the likelihood of infection increases, and vitamin E (a powerful antioxidant) and folic acid can improve the immune response, thereby reducing the risk of $\mathrm{BV}[18,19]$.

But since there is a relationship between taking ascorbic acid and boosting the immune system, the diet must be rich in products containing vitamin C. In addition, it has been shown that subclinical iron deficiency (measured based on soluble transferrin receptor) can be a significant predictor of BV [19].

An unbalanced diet can be a risk factor for BV, because it affects the microbial population of the mucosal surface in the digestive and reproductive tracts. In turn, bacterial colonization of the intestine can act as a reservoir for the vaginal microflora. Antonio et al. found agreement between Lactobacillus species in the rectum and vagina, suggesting that the rectum may serve as a potential source of vaginal colonization. The authors suggest that the adhesion properties of specific bacteria in the rectum may determine which species adhere to the vaginal epithelium [20].

In a recently published study, Tuddenham et al. proved that lower energy-adjusted intake of betaine was associated with an increased risk of molecular-BV. Betaine might have direct effects on the vaginal microenvironment or may be mediated through the gut microbiota. Betaine can be found in the diet in such products as bran and wheatgerm, goji berries, spinach or beets [21].

Additional studies are needed to confirm that higher intake of selected dietary ingredients, such as betaine, reduces the risk of BV and BV-related symptoms [21].

\section{THE ROLE OF PROBIOTICS IN THE PREVENTION AND TREATMENT OF BV AND VVC}

Probiotics are live microorganisms that, when administered in adequate amounts, confer a health benefit to the host [20]. Probiotics can be ingested as part of the diet or in supplement form [23, 24].

Probiotics have been reported to be useful when used either vaginally or orally [25].

The biochemical activity of probiotics (as a natural food ingredient or added as starter cultures) affects not only the nutritional, dietary and organoleptic characteristics of the product, but also has preventive and therapeutic effects. Probiotics are microorganisms, mainly lactic acid bacteria, that can colonize the human digestive tract. They may contain individual strains of lactic acid bacteria (Lactobacillus spp., Streptococcus spp.), strains of yeast (Saccharomyces spp.), mold cultures (Aspergillus spp.), or also lactic acid bacteria, together with selected yeast strains. Probiotics have a positive effect on gastrointestinal transit time and ensure the proper development of the microflora inhabiting the body. The word, probiotic' comes from Greek and means "fit for life". This term was first used in 1965 by Lilly and Stillwell, who described probiotics as substances produced by microorganisms that stimulate human and animal growth. Fuller added to the name in 1989 by defining that: , probiotics are live, bacterial food additives that improve the functioning of the host's digestive tract" [5].

In order to call a given bacterial strain a probiotic strain, it must come from the natural healthy microflora of the large intestine, be an absolute or relative anaerobic, and belong to a specific genus and species that has been assigned to it by molecular methods. It is advisable for it to be resistant to the acidic $\mathrm{pH}$ of gastric juice, bile salts and digestive enzymes. It should not exhibit pathogenic or toxic properties, and it is also recommended that it exhibits antagonistic activity against harmful gastrointestinal bacteria, have the ability to attach to the surface and colonize the colon, produces antibacterial substances, and have genetic stability. Active growth and division, as well as high lactic acid yield during fermentation of monosaccharides, disaccharides and complex sugars, is also important. Its positive effects should be scientifically confirmed and must retain all their properties in processing and storage. Most of these features allow probiotic bacteria to survive in the digestive tract and enter the large intestine, where they perform their functions. It has been proved that consuming probiotics has positive effects on the management of some gastrointestinal conditions (Irritable Bowel Syndrome, diarrhea). Probiotics can also counteract the pathogenic activity of microflora in the intestines, which penetrate as a result of non-compliance with food hygiene [9]. 
Probiotics are used after antibiotic therapy, and to produce functional food (especially milk products) and supplements [25-27].

The positive effects of probiotics on the immune system can be used to treat intestinal infections caused by HIV that penetrate the lining of the large intestine. The protective function is fulfilled by the previously mentioned biofilm constituting a natural immune barrier, and also by antibiotics produced by the intestinal microflora and the free radical lactactoxidase system. Probiotics can stimulate cellular and humoral immune responses. Many studies proved that regulated use of probiotics, administered both orally and vaginally, are effective in the prevention and treatment of vaginal infections such as BV and VVC $[23,24,28]$.

Bacterial vaginosis is characterized by a reduction or depletion of lactobacilli and overgrowth of Gardnerella vaginalis, Mycoplasma hominis, Prevotella species, and other pathogenic anaerobic bacteria [9].

The Lactobacillus species produces lactic and acetic acid and hydrogen peroxide $\left(\mathrm{H}_{2} \mathrm{O}_{2}\right)$, maintains the vaginal $\mathrm{pH}$ around 4.5 or less, hampers the growth of pathogenic bacteria and Candida albicans, and is thus considered protective against VVC and BV $[28,29]$.

Due to the production of lactic acid by probiotics, the electro-chemical potential of cell membranes and intracellular protein denaturation of harmful microflora are neutralized. Hydrogen peroxide is toxic to pathogens. Probiotics destroy pathogens as a result of their competing for nutrients and for receptors in the mucosa and epithelium. They also produce bacteriocins that remove pathogens from the digestive tract. They are heterogeneous chemicals that inhibit the activity of pathogenic bacteria - Staphylococcus aureus, Salmonella enteritidis, Bacillus cereus, or Pseudomonas aeruginosa, are mainly produced by Lactobacillus acidophilus. Bastani confirmed the potential efficacy of lactobacilli as a non-chemotherapeutic means to restore and maintain normal urogenital flora, and showed that probiotic bacteria especially $L$. acidophilus, L. rhamnosus $G R-1$ and $L$. fermentum RC-14 when administered over $10 \wedge 8$ CFU for 2 months can most appropriately normalize vaginal flora, help cure the existing infection and prevent recurrence of BV. Longer periods of probiotic administration may be useful for long-term control of BV relapses after conventional therapy with metronidazole [25].

According to Xie HY et al., probiotics used as adjuvant therapy may increase the incidence of short-term clinical and mycological cure and reduce the relapse rate within one month, but not act as a long-term cure. The benefits and drawbacks of probiotics in vulvar and vaginal candidiasis in non-pregnant women should be considered carefully.

There is a need to conduct large-scale, long-term, randomized control tests with adequate blindness of participants and staff, and to do so in different age groups. Where probiotics are intended to be used as adjunct agents to conventional drugs, a placebo should be used in the control group. The effect of different strains should also be checked, and possible effects from different routes of administration observed [30].

\section{THE IMPORTANCE OF PREBIOTICS AND SYNBIOTICS IN THE DIET}

To create a positive environment for probiotics, it is important to provide prebiotics that support the development of probiotic strains. Prebiotics are defined as non-digestible food ingredients that selectively stimulate the growth or activity of one or a specified number of types of bacteria in the colon that favorably affect the health of the host. Prebiotics can be introduced artificially into foods to improve the nutritional and health value, e.g. inulin, fructooligosaccharides, lactulose, or galactose and $\beta$-glucan derivatives. They are a breeding ground for probiotics, stimulate their growth and, unlike them, do not contain microorganisms. Prebiotics are not digested by endogenous enzymes in the human body, remain practically undigested as they reach the colon, where they are completely fermented and broken down by saccharolytic bacteria (e.g. Bifidobacterium) [13].

The basic criteria that prebiotics should meet are that they should lower the $\mathrm{pH}$ of the digestive tract and should not undergo hydrolysis or absorption through the gastrointestinal tract. Their task is also to stimulate the growth of lactic acid bacteria and inhibit the activity of harmful intestinal microflora. It has been proved that prebiotic consumption is associated with growth of Bifidobacterium, Lactobacillus and lactic acid bacteria [31]. Researchers suggest that consumption of prebiotics has a positive impact not only on gut microbial composition, but also on health outcomes, because probiotics produce beneficial metabolites [13].

Studies have shown that ingestion of prebiotics significantly affects the composition of the intestinal microflora and its metabolic activity. This is due to the modulation of lipid metabolism, increased calcium absorption, their impact on the immune system and modification of intestinal function. Prebiotics occur naturally in over 36,000 plant-derived products, including garlic (9-16\%), chicory (13-20\%), artichokes (15-20\%), asparagus (10-15\%), onions (2-6\%), wheat (1-4\%) and bananas (0.3-0.7\%) [9]. Artificially produced prebiotics include lactulose, galactooligosaccharides, fructooligosaccharides, malotoligosaccharides, cyclodextrins and lactosaccharose. Synbiotics are a combination of pre- and probiotic and these have a synergistic effect. They affect the development of beneficial intestinal microflora due to stimulation of probiotics with prebiotics. They also inhibit the development of pathogenic bacterial flora in the intestines. Synbiotics contribute to reducing the concentration of unwanted metabolites in the body, inactivat- 
ing nitrosamines and carcinogens, as well as preventing putrefaction in the intestines and preventing constipation and diarrhea of various etiologies. Synbiotics also reduce harmful microflora (Clostridium perfringensi of other endopathogens) while multiplying beneficial bacteria. They lower cholesterol and blood pressure and are used to treat patients with liver disease [9]. They improve the absorption of magnesium and phosphorus and calcium, which, as mentioned, has a beneficial effect on the prevention of inflammation in gynecology $[1,4,5,7-9]$.

\section{SUMMARY}

Gynecologists, obstetricians, general practitioners and dieticians should share their findings, and also raise awareness among the general population as to the importance of optimal nutrition, probiotics and prebiotic use to prevent infections of the genital tract, reduce associated disease, and maintain reproductive health.

Future reviews investigating dietary and biochemical indicators of nutritional status, and the role of diet in changes to gut and vaginal microbiome need to focus on further elucidating the biological mechanisms for these findings.

Further research is needed on the long-term influence of diets and probiotics use on vulva and vagina health before clinical recommendations can be made.

\section{REFERENCES}

1. Jarząbek-Bielecka G, Pawlaczyk M, Pisarska-Krawczyk M, et al. The problem of inflammation of the female genital system - assessment of girls' knowledge about prevention and treatment. Med Rodz. 2018; 21(1A): 29-36.

2. Paladine HL, Desai UA. Vaginitis: Diagnosis and Treatment. Am Fam Physician. 2018; 97(5): 321-329.

3. Thoma ME, Klebanoff MA, Rovner AJ, et al. Bacterial vaginosis is associated with variation in dietary indices. J Nutr. 2011; 141(9): 1698-1704, doi: 10.3945/jn.111.140541, indexed in Pubmed: 21734062.

4. Pawlaczyk M, Jarząbek G, Pawlaczyk M, et al. Vulvar disease, vulvovaginitis in adolescent girl. Ginek Prakt. 2006; 1(14): 116-118.

5. Skłodowska A, Pawlaczyk M, Jarząbek G, et al. Aspekty kliniczne zapalenia sromu i pochwy u dziewczynek w wieku przedpokwitaniowym (Clinical aspects of vulvovaginitis in pre-pubertal girls). Przegl Derm. 2011; 1(98): 48-49.

6. Jarząbek-Bielecka G, Pawlaczyk M, Pisarska-Krawczyk M. Zapalenia sromu i pochwy po menopauzie. In: Pisarska-Krawczyk M, JarząbekBielecka G. ed. Zagadnienia interdyscyplinarne w ginekologii praktycznej. Wydawnictwo Uczelniane PWSZ, Kalisz 2014.

7. Jarząbek-Bielecka G, Pawlaczyk M, Pisarska-Krawczyk M, et al. Sexually transmitted diseases in adolescents. Current Gynecologic Oncology. 2015; 13(1): 20-26, doi: 10.15557/cgo.2015.0003.

8. Jarząbek-Bielecka G. Srebro TIAB a zapalenia i zakażenia narządów płciowych, ze szczególnym uwzględnieniem pacjentek w wieku rozwojowym (TIAB silver and genital inflammation and infections, with a special focus on patients in developmentalal age). Anal Przypadków Ginek Położ. 2017; 1(18): 20-22.

9. Sobel J. Vulvovaginal candidosis. The Lancet. 2007; 369(9577): 19611971, doi: 10.1016/s0140-6736(07)60917-9.

10. Jagodzinski A, Zielinska E, Laczmanski L, et al. The early years of life. Are they influenced by our microbiome? Ginekol Pol. 2019; 90(4): 228-232, doi: 10.5603/GP.2019.0041, indexed in Pubmed: 31059117.

11. Statement of the Polish Gynecological Society Expert Group on the use of ellen. Ginekol Pol. 2012; 83(8): 633-638.
12. Dankovich N. New opportunities in preparation of women with reproductive tracts microbiocenosis disorder for gynaecologic intervention. Women Health. 2006; 2: 1-6.

13. Leeming ER, Johnson AJ, Spector TD, et al. Effect of Diet on the Gut Microbiota: Rethinking Intervention Duration. Nutrients. 2019; 11(12), doi: 10.3390/nu11122862, indexed in Pubmed: 31766592.

14. Parsapure R, Rahimiforushani A, Majlessi F, et al. Impact of Health-Promoting Educational Intervention on Lifestyle (Nutrition Behaviors, Physical Activity and Mental Health) Related to Vaginal Health Among Reproductive-Aged Women With Vaginitis. Iran Red Crescent Med J. 2016; 18(10): e37698, doi: 10.5812/ircmj.37698, indexed in Pubmed: 28184325.

15. Al-Ghazzewi FH, Tester RF. Biotherapeutic agents and vaginal health J Appl Microbiol. 2016; 121(1): 18-27, doi: 10.1111/jam.13054, indexed in Pubmed: 26757173.

16. Neggers Y, Nansel T, Andrews W, et al. Dietary Intake of Selected Nutrients Affects Bacterial Vaginosis in Women. J Nutr. 2007; 137(9): 2128-2133, doi: 10.1093/jn/137.9.2128.

17. Tilg H. Obesity, metabolic syndrome, and microbiota: multiple interactions. J Clin Gastroenterol. 2010; 44 Suppl 1: S16-S18, doi: 10.1097/MCG.0b013e3181dd8b64, indexed in Pubmed: 20535027.

18. Neggers $\mathrm{YH}$, Nansel TR, Andrews WW, et al. Dietary intake of selected nutrients affects bacterial vaginosis in women. J Nutr. 2007; 137(9): 2128-2133, doi: 10.1093/jn/137.9.2128, indexed in Pubmed: 17709453.

19. Westney OE, Westney LS, Johnson AA, et al. Nutrition, genital tract infections, hematologic values, and premature rupture of membranes among African American women. J Nutr. 1994; 124: S987-S993.

20. Antonio MAD, Rabe LK, Hillier SL. Colonization of the rectum by Lactobacillus species and decreased risk of bacterial vaginosis. J Infect Dis. 2005; 192(3): 394-398, doi: 10.1086/430926, indexed in Pubmed: 15995952.

21. Tuddenham S, Ghanem KG, Caulfield LE, et al. Associations between dietary micronutrient intake and molecular-Bacterial Vaginosis. Reprod Health. 2019; 16(1): 151, doi: 10.1186/s12978-019-0814-6, indexed in Pubmed: 31640725 .

22. Report of a joint FAO/WHO expert consultation on evaluation of health and nutritional properties of probiotics in food including powder milk and live lactic acid bacteria [Internet]. Cordoba, Argentina: Food and Agriculture Organisation (FAO)/World Health organisation (WHO). 2001. http://www.fao.org/3/a-a0512e.pdf (2.01.2018).

23. Jarde A, Lewis-Mikhael AM, Moayyedi $P$, et al. Pregnancy outcomes in women taking probiotics or prebiotics: a systematic review and meta-analysis. BMC Pregnancy Childbirth. 2018; 18(1): 14, doi: 10.1186/s12884-017-1629-5, indexed in Pubmed: 29310610.

24. Buggio $L$, Somigliana $E$, Borghi $A$, et al. Probiotics and vaginal microecology: fact or fancy? BMC Womens Health. 2019; 19(1): 25, doi: 10.1186/s12905-019-0723-4, indexed in Pubmed: 30704451

25. Bastani P, Homayouni A, Gasemnezhad V, et al. Dairy Probiotic Foods and Bacterial Vaginosis: A Review on Mechanism of Action. Probiotics. 2012, doi: $10.5772 / 50083$

26. Ford AC, Quigley EMM, Lacy BE, et al. Efficacy of prebiotics, probiotics, and synbiotics in irritable bowel syndrome and chronic idiopathic constipation: systematic review and meta-analysis. Am J Gastroenterol. 2014; 109(10): 1547-61; quiz 1546, 1562, doi: 10.1038/ajg.2014.202, indexed in Pubmed: 25070051.

27. Goldenberg J, Yap C, Lytvyn L, et al. Probiotics for the prevention of Clostridium difficile-associated diarrhea in adults and children. Cochrane Database Syst Rev. 2017, doi: 10.1002/14651858.cd006095.pub4.

28. Ma L, Su J, Su Y, et al. Probiotics administered intravaginally as a complementary therapy combined with antibiotics for the treatment of bacterial vaginosis: a systematic review protocol. BMJ Open. 2017; 7(10): e019301, doi: 10.1136/bmjopen-2017-019301, indexed in Pubmed: 29038188.

29. Reid G, Younes JA, Van der Mei HC, et al. Microbiota restoration: natural and supplemented recovery of human microbial communities. Nat Rev Microbiol. 2011; 9(1): 27-38, doi: 10.1038/nrmicro2473, indexed in Pubmed: 21113182.

30. Xie HYu, Feng D, Wei DM, et al. Probiotics for vulvovaginal candidiasis in non-pregnant women. Cochrane Database Syst Rev. 2017; 11: CD010496, doi: 10.1002/14651858.CD010496.pub2, indexed in Pubmed: 29168557.

31. So $D$, Whelan $K$, Rossi $M$, et al. Dietary fiber intervention on gut microbiota composition in healthy adults: a systematic review and meta-analysis. Am J Clin Nutr. 2018; 107(6): 965-983, doi: 10.1093/ajcn/nqy041, indexed in Pubmed: 29757343. 